\title{
Facing Societal Challenges: The Need for New Paradigms in Rural Transit Service
}

\author{
Sandra Rosenbloom \\ The Roy Drachman Institute \\ University of Arizona, Tucson
}

\begin{abstract}
In response to major societal trends, rural transit operators should consider different ways to organize, design, and deliver public transit services. This article summarizes societal changes affecting rural areas and identifies five "new paradigms" in rural service organization and delivery to meet the needs created in many rural areas. The article concludes that many operators in a variety of rural settings could enhance their role and better meet the transportation challenge of a changing population by adopting different service paradigms.
\end{abstract}

\section{Introduction}

A U.S. Department of Agriculture (USDA) report noted that:

Rural America has changed in many ways over the century. The rural economy in particular has changed-shifting from a dependence on farming, forestry, and mining to a striking diversity of economic activity. ...[W] hile it continues to provide most of the Nation's food and fiber, rural America has taken on additional roles, providing labor for industry, land for urban and suburban expansion, sites for storage of waste and hazardous activities, and natural settings for recreation and enjoyment. (USDA 1997) 
In response to these changes, the Transit Cooperative Research Program (TCRP) of the National Research Council has suggested that rural operators must move beyond traditional service approaches by developing "new paradigms" or different ways to organize, design, and deliver public transit services in response to the range of economic, social, and political challenges they face (TCRP 1999). This means moving beyond both direct service delivery to traditional clients and dependence on traditional sources of finance and support. This article reports on a study arising from TCRP's emphasis on new transit paradigms. The study proposed five rural paradigms that represent a new way of thinking about the role of the transit operator and a new definition of mobility.

This article first summarizes a complex set of interrelated forces facing rural areas. The following section suggests ways in which rural operators could enhance their role to better meet the transportation challenge of a changing population by adopting five different service paradigms.

\section{Profound Societal Changes}

Massive societal changes may have complex implications because they create within rural areas new, different, and varied:

- housing and residential concentrations,

- community economic bases, and

- public and private service delivery systems.

Not all societal trends have the same impact in all rural areas nor do they always have major transportation implications. But most do, both directly and indirectly, because they affect the relationship of home to work, the origins, schedules, and destinations of a range of trips, the trade-offs between travel and other activities, the ability of people to give or receive transport or other services in their communities, and the capacity of communities themselves to meet rural mobility needs.

\section{Changes in Housing and Residential Concentrations}

Before 1990 most rural areas lost population due to out-migration of younger workers and their families (Johnson and Beale 1999). Although families dependent on agriculture or mining have continued to leave, rural areas in most parts of the United States experienced population gains beginning in 1990 (USDA 1997) due entirely to in-migration - both from metro regions and from abroad (Beale 1999). 
These changes had six major components:

1. An influx of young commuters and their families (Nord and Cromartie 1999)

2. Increasing immigration of retirees (Rogers 1999a and b; Fagan and Reeder 1996; Stallman and Siegel 1995; Snyder 1994)

3. Increasing concentrations of older people aging in place (Rogers 1999a; USDA 1997)

4. Growing rural concentrations of minority populations (Cromartie 1999; Swanson 1999; USDA 1997)

5. Changing family structures and living patterns, particularly the growth of households headed by single women and increasing labor force involvement of women with children (Rogers 1999b)

6. Continued suburbanization (Aldrich et al. 1997; Campanelli 1994; Forstall 1993)

These population changes have created a far more complex set of rural travel patterns and mobility needs. Many rural residents are commuting long distances to suburban or central city jobs in adjacent metro areas or rural jobs in different counties. Internal travel trends are also changing as the influx of both younger and older people — with different needs, abilities, and resources—plays out in changing travel patterns. In-migrant retirees, older people aging in place, ethnic minorities, poor families, and the increasing participation of women in the labor force have created growing mobility needs, even as the ability of family, friends, and community resources to meet those needs may be declining.

\section{Changing Community Economic Bases}

Rural areas have traditionally based their economies on farming, fishing, forestry, and/or mining-industries that have been declining nationally for more than three decades. At the same time there has been a sometimes startling increase in nontraditional rural employment.

Analyses show five major national economic changes in rural areas:

1. Declining role of agricultural and other land-based industries (USDA 1997; Nelson and Beyers 1998)

2. Expanding manufacturing base (McGranahan 1998; Gordon and Richardson 1998; Roth 2000) 
3. Growth of an amenities-based service sector (McGranahan 1998; Freshwater 2000; Cromartie 1998)

4. Growth of a retirement-based service sector (Glascow and Reeder 1990; Hodge 1991; Schneider and Green 1992; Stallman and Siegel 1995; Day 2000)

5. Growth of other service sector industries (Beale 1996; Bell and Everett 1997; U.S. General Accounting Office 1997)

These economic trends have also created new and different worktrip patterns. Growing rural manufacturing and large-scale tourism and casinos have created employment concentrations within rural areas that not only provide a rural worktrip focus, but also draw workers from adjacent rural and metro areas. Some rural residents who once worked on farms or in mines now have jobs in local manufacturing plants, tourist destinations, or prisons.

The larger shift to a service economy creates greater variability in the timing and scheduling of work and other trips. Only a minority of service sector workers commute during traditional morning and afternoon peaks; many work different hours on different days. And multijob holding, which has helped some rural families rise above poverty level, creates even more complex and complicated travel patterns.

These trends also affect the ability of rural communities to respond to transportation needs. Many of the jobs created by retirement- or amenities-driven industries are low-skill and low-wage jobs, which partially explains why so many rural working families still live at or below the poverty level. Although these jobs do bring additional income into the community, local residents, including those aging in place, may have even higher demands for governmental or social services. Rural workers who commute out of the area for employment may spend most of their money near their metro area jobs. But at the same time, new rural industries or casinos may be willing to pay for transit services for employees or develop child care facilities for working mothers.

\section{Changes in Public and Private Service Delivery Systems}

In the last decade there have been almost unprecedented changes in transportation, communications, and service delivery systems in both rural and urban areas. In some instances these changes have been accompanied by major shifts in government programs and policies. From welfare reform to deregulation in the communications sector, rural areas are being challenged by new situations. Research suggests four major trends in these areas: 
1. Advances in production and communications technology (U.S. Department of Commerce 1995; Gibbs and Bernat 1997; Kusmin 1996; McGranahan 1998; Gordon and Richardson 1998)

2. Competition and deregulation in the communications industry (USDA 1997; U.S. Department of Commerce 1995; Stenberg et al. 1997; Van Wart et al. 2000)

3. Changes in rural transit service delivery (Midwest Transportation Center 1996; North Carolina State 1999; Black 1999)

4. Changing patterns of rural health care (Spann 1994; Ricketts and Slifkin 1995; Powers 1996; Perch et al. 1997; Blank 1999; U.S. General Accounting Office 2000)

New commuter patterns may arise as some rural areas attract high-tech and "newtech" firms that can locate outside major metropolitan areas because of new communications and other technology. Competition and deregulation in the communications industry can help narrow the social and economic gaps between rural and urban areas, making rural areas more attractive places to live or visit, changing a variety of travel patterns, and even creating rural congestion. Advances in communications technologies may affect both industry and the ways in which community transportation providers can respond to changing needs in low-density areas. The most obvious example is the growing use by rural transit providers of computer dispatching based on satellite communications.

Public policies can have profound rural impacts. For example, even as rural hospitals close in response to Medicare cost-containment policies, Heath Maintenance Organizations (HMOs) and other managed care programs are moving into rural areas in unprecedented numbers. This may provide more convenient medical options for some rural residents, changing medical travel and even creating new work commutes within rural areas (Ricketts and Slifkin 1995; Frenzen 1997; Kohrs 1997). 


\section{New Service Paradigms in Rural Transportation}

In 1997 the Transportation Research Board established a New Paradigm Project which asserted:

[L]ocal public transit organizations and the services they currently provide are being marginalized at every turn. More specifically, traditional transit organizations:

- have been slow to adapt to fundamental changes throughout society,

- are facing circumstances that threaten their continued relevance in the future, and

- must act out of a renewed sense of urgency to reinvent themselves as agile, responsive, and responsible "managers of mobility" (TCRP 53, 1999, p. ES 1).

The study reported on here suggests that transit operators in rural areas are in a position to take advantage of opportunities by adopting five alternative approaches to meeting rural mobility needs:

1. Serving as community change agents

2. Optimizing community transportation resources

3. Becoming early adopters of technology and innovation

4. Acting as public entrepreneurs

5. Providing state-of-the-art service

The specific services, partnerships, or strategies that can support these paradigms are identified in Table 1 on the following pages.

\section{Community Change Agents}

Arguably the most important role for a rural transit system is to become an active participant in all decisions about how and where communities grow and develop. Land-use and development patterns profoundly impact the competitiveness, cost, and efficiency of transit services. Transit staff should sit on all local, county, or regional governmental committees involved in economic development, land use, or housing policies to become more aware of the potential for new and different services. By doing so, transit operators can learn about emerging population and industrial trends and influence land use and development to benefit transit. This interaction also gives the transit system a timely window of opportunity to sug- 
gest site-specific exactions (e.g., requiring a firm to construct covered transit stops adjacent to the front entrance), urge firms to offer employees transit passes, or provide funding for specially designed commuter (or other) services.

At the same time rural transit officials can actively work to create denser patterns that make public transit more attractive and efficient. While rural areas will never develop high-density patterns, some commercial, industrial, and public activities can be concentrated in these regions, making public transit more attractive to potential users and service provision more efficient. When transit agencies locate facilities (e.g., transfer points or terminals), they should carefully chose sites that bring transit closer to active land uses.

\section{Optimizing Community Transportation Resources}

Automobiles are the dominant transportation mode in rural areas-and the greatest resource available in those communities. An equally important resource is the large number of capable drivers. By viewing their mandate as providing mobility rather than just transit service, rural transit operators could facilitate the optimal use of these vehicles and drivers by implementing a variety of ways to share both private and public vehicles. Rural transit operators could facilitate the better utilization of empty seats in privately driven cars through ordinary carpooling and matching programs or by developing more inventive programs, using the power of new communications technology to offer real-time car sharing.

Rural systems could also facilitate one driver using the private vehicle owned by another when that driver is not using it. A rural operator could also implement a car-sharing variation based on schemes tried in a few urban areas. Large residential complexes, like trailer parks or naturally occurring retirement neighborhoods, could cooperatively buy and operate a small fleet of vehicles with a system that allowed individual residents to reserve and drive them, with payment and other rules known in advance. Rural transit systems could encourage residential areas to set up their own programs or actually purchase and maintain the vehicles. Rural operators could also become car rental agencies, maintaining a fleet of vehicles for the sole purpose of rental to rural residents.

Rural operators could also provide a mechanism through which other public or nonprofit agencies could effectively sell (or barter) the underutilized capacity of their vehicles. The transit system role might include developing a matching process, providing regional maintenance facilities, supplying group insurance or umbrella policies to facilitate sharing, and/or offering driver training programs to the 


\section{OPTIMIZING COMMUNITY TRANSPORTATION RESOURCES}

\section{Facilitate car sharing programs}

- utilize extra capacity in SOV's

- effectively share POV down time

- facilitate residential car sharing

- use public vehides more effectively

\section{Coordinate shared vehicle use}

- design mechanism to sell excess capacity

- operate regional maintenance centers

- supply group insurance or pool

- offer driver training for agency staff

Fadilitate innovative volunteer programs

- pay volunteers when efficient

- pay friends/family for cost-effective trips

- pay people to provide feeder services

\section{Organize vehide purchase} schemes

- trade local match for used vehicles - facilitate joint vehide purchase

\section{ADOPTING TECHNOLOGY AND INNOVATION}

\section{Implement SOA communications and dispatch} technology

- implement overal improvements

- develop statewide computer and GIS applications

- coordinate with State emergency systems

\section{Bank transportation credits}

- develop transportation savings accounts

- implement pre-paid options

- develop service-for-service accounts

\section{Provicle transportation}

insurance

- develop long term relationship with appropriate agencies

\section{BECOMING PUBLIC ENTREPRENEURS}

\section{Expand contract delivery of transport senvices}

- contract with urban and suburban operators

- provide service to urban social service agencies

\section{Sell delivery senices}

- contract with local stores for rural deliveries

- contract with freight companies

- provide urban delivery service for rural residents

\section{Provide altematives to travel}

- deliver goods instead of rides

- organize volunteers to provide services in lieu of travel 


\section{SERVING AS COMMUNITY CHANGE AGENTS}

\section{Become active in community decision making}

- serve on all economic development and land use policy committees

- seek transit concessions from new industry

- ensure meaningful transit access in new facilities/ plants

\section{Help create rural trip concentrations}

- facilitate the co-location of rural services

- encourage concentrated developments

- ensure appropriate transit services

\section{Locate transit facilities near}

major trip attractors

- provide transfer and other facil-

ities near major commercial sites

\section{PROVIDING STATE-OF-THE-ART SERVICE}

\section{Expand senvices to match user needs}

- restructure routes, schedules, services

- consider services for urban commuters

- encourage vanpooling options

- provide services to children

- provide special scheduled services

\section{Use most cost-effective providers}

- contract fro low productivity services

- pay volunteers for feeder services

- create and support local transportation

providers
Differentiate senices by fare

- offer special services at premium prices to attract new users

- set fares to shift travel to off-peak

- use fares to achieve group travel 
personnel of cooperating agencies. A rural transit operator could also act as a facilitator in the joint grant purchase of one vehicle by two (or more) agency providers.

Rural operators could also expand the volunteer-based services they have long used by paying volunteers to provide services too expensive for the system to directly provide. For example, rural operators could pay local drivers more than simple mileage charges or directly or indirectly (through user-side subsidies) pay family and friends to provide transport services for people living in areas or traveling at times when it was not efficient for the operator to respond.

\section{Becoming an Early Adopter of Technology and Innovation}

In industry, early adopters of technology usually surge to the head of their field. Rural transit operators can focus on both improvements in communications and dispatching technology and innovative institutional ways to capture and bank transportation resources. Potential technological strategies include overall improvements in communications and dispatching, statewide application and real-time support of technology, and coordinating improvements with state advances in rural emergency systems. Two recent TCRP projects (B-17 and A-21) concluded that there was wide scope for rural systems to implement a variety of basic or advanced technology and the use of Geographic Information Systems (GIS) databases to improve system efficiency.

In addition, many states are gradually developing statewide emergency systems, based on a variety of communications technologies. But emergencies, while extremely serious in low-density rural areas, are fairly rare and the system and equipment are substantially underutilized on a daily basis. The transit system could use the emergency system to deliver real-time information to riders waiting for service, to assist in real-time dispatching, and to improve data collection through automatic message systems.

There are also institutional innovations open to rural operators: two were first suggested by the Independent Transportation Network (ITN) system in Portland, Maine. Rural systems can develop a way for residents to "bank" transportation rides for future transport needs. Residents or family members can save for services they or their relatives need now or in the future. Residents could also offer services as drivers, escorts, or dispatchers and have rides credited to their own "transportation bank account" or that of a family member for immediate or future use. The transit operator could also offer transportation "insurance" not unlike medical 
insurance, where people pay in over the years for guaranteed transportation services sometime in the future.

\section{Multifunction Public Entrepreneurs}

Public agencies can adopt a more entrepreneurial focus without abandoning interest in nonmonetary factors such as customer comfort or the needs of lowincome people. Instead, as entrepreneurs, rural operators would focus more clearly on the customers, exploit every opportunity to increase whatever they see as the bottom line, and consider carefully how to maximize their output given their scarce resources. Acting as public entrepreneurs, rural operators could expand contract transport services to nontraditional clients, provide alternatives to travel, and sell delivery or other nonclient services to the private sector.

Although many rural providers currently offer some contract services, they could more aggressively pursue contract arrangements with both suburban and urban operators. A rural operator with downtime in urban areas (created, for example, by transporting rural workers to metro area jobs) could seek contracts with an urban transit operator or the Area Agency on Aging (AAA), etc. The rural operator could then provide congregate meal service, grocery shopping, or American with Disabilities Act (ADA) services to urban residents during the middle of the daymaking money on what would otherwise be costly "dead" time.

Rural operators could also expand some of the services in which they already engage (e.g., meal deliveries) by contracting with private entities needing home deliveries. By coordinating the delivery of other goods-ranging from prescriptions to dog food-with either meal delivery or regular transportation services, operators could substantially increase their income. And, they might even reduce the need for travel by rural residents; the system could occasionally offer the delivery of groceries in lieu of a trip to the grocery store when capacity is limited or the grocery trip is difficult to serve during specific time periods. Delivery services could even be provided by a coordinated system of volunteer drivers (and perhaps shoppers).

Rural systems could become even more entrepreneurial by contracting with private delivery firms to deliver packages. In many smaller areas, national or regional freight delivery firms have only contract providers, rather than directly making delivery themselves. The rural operator could even offer a fee-based delivery service to rural residents by taking packages to an urban post office on passenger runs into urban areas. In addition, the transit operator could make urban goods deliv- 
eries for rural residents, such as delivering specialty agricultural items to urban restaurants or farmers markets.

\section{State-of-the-Art Service Providers}

Local operators must move beyond the services they have traditionally provided, offering alternatives to new markets and new trips, expanding institutional arrangements, and seeking new partnerships. Some rural systems have been extremely innovative in this area. A recent Community Transportation Association of America (CTAA) study for the Federal Transit Administration (FTA) found that rural operators have not only expanded their vehicle fleets and the number of passengers served in the last decade but have also extended their service areas and begun providing new and different travel options (CTAA 2001).

Although some rural systems have expanded their role, not all systems have taken advantage of opportunities. Even the more innovative systems have not gone as far as they can. Overall, rural operators need to actively seek opportunities to expand service offerings to match a range of user needs, matching the most appropriate provider to each market niche (rather than viewing direct service as the first or only response) and differentiating services by fares.

Rural operators should consider route and service restructuring; park-and-ride and express services for suburban and urban commuters; vanpooling for local, regional, and metropolitan commuters; transport for child care and after-school care; and specific services geared to families and older people. Rural operators should also consider a wider range of potential contract providers, using paid "volunteers" more frequently and perhaps "growing" their own subcontractors. In a program funded by the FTA, the University of Tennessee trained welfare recipients to become transportation entrepreneurs. Three of the firms started by this program are now actively involved in a range of contract services for the transit operator itself and for other local agencies needing client services (Newsom et al. 2000).

Rural operators should also consider using fare differentials to promote some services over others or to expand services to higher-income users by charging premium prices for premium service. Operators can use lower fares to encourage people to travel in the off-peak (or whenever demand is lowest), to induce either the general public or clients of social service agencies to group trips, and to motivate users to call in advance rather than seeking real-time service (or vice versa). 


\section{Summary and Implications}

Many societal trends create problems for rural operators providing traditional services. At the same time, these trends offer opportunities for rural providers to view themselves in new ways, more effectively meeting a range of mobility needs now and in the future. This article has suggested five paradigms that rural operators can adopt to take advantage of their opportunities.

To create systems that continually seek innovative solutions, plan for ongoing change, and act instead of merely react, rural operators need to do more than adopt interesting or novel ideas. Rural operators need to substantially modify how they view themselves and the strategies they employ to provide services. In fact, it is only when rural operators begin by adopting nontraditional organizational structures and new approaches to service delivery that they develop, adapt, and adopt a wide range of innovative ideas and services to better meet their changing community needs.

\section{Acknowledgements}

Some of the research reported on in this article was performed under TCRP Project B-22 by the Roy P. Drachman Institute of the University of Arizona. The author is grateful to the TCRP panel and staff for important insights and suggestions. Ghazal Farhang and Emily Steemsa Leunk, research staff at the Drachman Institute, made major contributions. All opinions, recommendations, errors, and omissions are the responsibility of the author. 


\section{References}

Aldrich, L., C. Beale, and K. Lassel. 1997. Commuting and the economic functions of small towns and places. Rural Development Perspectives 12(3):26-31.

Beale, C. 1999. Nonmetro population rebound: Still real but diminishing. Rural Conditions and Trends 9(2):20-27.

Beale, C. 1996. Rural prisons: An update. Rural Economic Development Perspectives 11(2):25-27.

Bell, D., and K. Everett. 1997. Effective strategies for the future of rural communities. Economic Development Review 15(1):89-92.

Black, T. 1999. Bringing ITS to rural America. American City and County 14(1).

Blank, D. 1999. Code blue for small hospitals. Business Week 8143:6.

Campanelli, M. 1994. Rural sprawl. Sales and Marketing Management 16(7):43-45.

Community Transportation Association of America. 2001. Status of Rural Public Transportation-2000. Washington, DC: Federal Transit Administration. http:/ /www.ctaa.org/ntrc/rtap/pubs/status2000.

Cromartie, J. B. 1999. Minority counties are geographically clustered. Rural Conditions and Trends 9(2):14-19.

Cromartie, J. B. 1998. Net migration in Great Plains increasing linked to natural amenities and suburbanization. Rural Development Perspectives 14(1):27-34.

Day, F. 2000. Economic impact of retirement migration on the Texas Hill Country. Journal of Applied Gerontology 30:457-490.

Fagan, M. and R. Reeder. 1996. Communities may lose military retirees along with their bases. Rural Development Perspectives 11(3):17-22.

Forstall, R. L. 1993. Going to town. American Demographics 15(5):42-48.

Frenzen, P. D. 1997. How will measures to control medicare spending affect rural communities? Issues in Rural Health, Agricultural Information Bulletin 734:110.

Freshwater, D. 2000. Rural America at the turn of the century: One analyst's perspective. Rural America 12(2).

Gibbs, R. M., and G. A. Bernat, Jr. 1997. Rural industry clusters raise local earnings. Rural Development Perspectives 12(3). 
Glascow, N., and R. Reeder. 1990. Economic and fiscal implications of nonmetropolitan retirement migration. Journal of Applied Gerontology 9(2):433-451.

Gordon, P., and H. Richardson. 1998. Metropolitan and nonmetropolitan growth trends in the US: Recent evidence and implications. Urban Studies 35(7):10371058.

Hodge, G. 1991. The economic impact of retirees on smaller communities: Concepts and findings from three Canadian studies. Research on Aging 13(1):3954.

Johnson, K. M., and C. Beale. 1999. The continuing population rebound in nonmetro America. Rural Development Perspectives 13(3):2-10.

Kohrs, F. R. 1997. Can market-based solutions work for all medicare? Barriers to reform in the medicare population residing in health professional shortage areas. Southern Medical Journal 90: 493-497.

Kusmin, L. D. 1996. Computer use by rural workers is rapidly increasing. Rural Development Perspectives 11(3).

McGranahan, D. A. 1998. Local problems facing manufacturers: Results of the Economic Research Service rural manufacturing survey. Agricultural Information Bulletin 736-703.

Midwest Transportation Center. 1996. Linking real time and location in scheduling demand-responsive transit. Final Report.

Nelson, P. B., and W. B. Beyers. 1998. Growth and Change 92(3):295-319.

Newsom, T.J., F. J. Wegmann, and T. O'Mary. 2000. A transportation business development program to enhance community-based mobility services in the Knoxville, TN, area. Technical Report. Knoxville, TN: University of Tennessee Center for Transportation Research.

Nord, M., and J. B. Cromartie. 1999. Rural areas attract young families and college graduates. Rural Conditions and Trends 9(2):28-34.

North Carolina State. 1999. Small Urban and Rural Advanced Transportation Systems. North Carolina State University and Institute for Transportation Research and Education. http://www2.ncsu.edu/eso/service/ce/research/stone_res/. 
Perch, A. et al. 1997. Recruitment of primary healthcare physicians in rural areas. Hospital Topics 75 (4):29-34.

Powers, M. 1996. Keeping rural American healthy. Human Ecology Forum 24 (1):37.

Ricketts, T. S., and R. T. Slifkin. 1995. Patterns of health maintenance organization service areas in rural counties. Health Care Financing Review 17(1): 99-114.

Rogers, C. C. 1999a. Changes in the older population and implications for rural areas. Research Report 90. Washington, DC: U.S. Department of Agriculture Economic Research Service.

Rogers, C. C. 1999b. Socioeconomic circumstances of minority elderly differ from those of white elderly. Rural Conditions and Trends 9(2):35-39.

Roth, D. 2000. Thinking about rural manufacturing: A brief history. Rural America 15(1).

Schneider, M. J., and B. L. Green. 1992. A demographic and economic comparison of nonmetropolitan retirement and nonretirement counties in the U.S. Journal of Applied Sociology 9(2):63-84.

Snyder, W. P. 1994. Military retirees: A portrait of the community. Armed Forces and Society 20(4):581-591.

Spann, S. 1994. Family medicine: A rational model for primary care around the world. Family Community Health 7(2): 45-51.

Stallman, J. I., and P. B. Siegel. 1995. Attracting retirees as an economic development strategy: Looking into the future. Economic Development Quarterly 9(4):372-383.

Stenberg, P. L., S. Rahman, M. Perrin, and E. Johnson. 1997. Rural areas in the new telecommunications era. Rural Development Perspective 12(3):32-38.

Swanson, L. 1999. Minorities represent growing share of tomorrow's work force. Rural Conditions and Trends 9(2):9-11.

Transit Cooperative Research Program. 1999. New paradigms for local public transportation organizations. Task 1 report, forces and factors that require consideration of new paradigms. TCRP Report 53. Washington, DC: National Academy Press. 
U.S. Department of Agriculture. 1997. Understanding rural America. Report AIB 710. $h t t p: / / w w w . e r s . u s d a . g o v / e p u b s / h t m l d o c / a i b 710$.

U.S. Department of Commerce. 1995. Survey of rural information infrastructure technologies. National Telecommunications and Information Administration, Special Publication 95-33.

U.S. General Accounting Office. 2000. Medicare and managed care plans: Payments and costs for selected hospitals. Report GAO/HEHS-00-177R.

Van Wart, M., D. Rahm, and S. Sanders. 2000. Economic development and public enterprise: The case of rural lowa's telecommunications utilities. Economic Development Quarterly 14(2).

\section{About the Author}

SANDRA Rosenbloom (rosenblo@u.arizona.edu) is professor of planning and director of the Drachman Institute at the University of Arizona. Dr. Rosenbloom is an internationally recognized expert on the impact of societal trends on transport planning. She has written extensively on transit and paratransit planning, emerging travel patterns of women, and growing needs of older people and those with disabilities. 